\title{
Depredación del escorpión Centruroides bicolor por la serpiente alacranera Stenorrhina degenhardtii (Squamata: Dipsadidae)
}

\author{
Alejandro Solórzano \\ Recibido 29-I-2018 • Corregido 03-II-2018 • Aceptado 02-IV-2018
}

Museo de Zoología, Universidad de Costa Rica, Ciudad Universitaria Rodrigo Facio, 2060 San José, Costa Rica; solorzano29@gmail.com

\begin{abstract}
Predation of the scorpion Centruroides bicolor by the Scorpion Eater Snake, Stenorrhina degenhardtii (Squamata: Dipsadidae). I present a photographic sequence of how the snake Stenorrhina degenhardtii captures and eats the scorpion Centruroides bicolor.
\end{abstract}

Key words: Scorpiones, Buthidae, snake predatory behavior, photographic documentation.
RESUMEN: Presento una secuencia fotográfica de cómo la serpiente Stenorrhina degenhardtii captura y come al escorpión Centruroides bicolor.

Palabras clave: alacrán, escorpión bútido, comportamiento depredador de una serpiente, documentación fotográfica.
Las serpientes alacraneras del género Stenorrhina (Dipsadidae), que habitan desde el sur de México hasta el norte de Sudamérica, se caracterizan por sus hábitos alimenticios especializados en organismos invertebrados, incluyendo principalmente arácnidos (tarántulas y escorpiones) y diversos tipos de insectos (Solórzano, 2004; Solórzano \& Greene, 2011). En Costa Rica, la alacranera sureña Stenorrhina degenhardtii habita en bosques lluviosos de baja y mediana elevación en el Pacífico central y sur y en la vertiente del Caribe.

Durante la mañana del 14 de noviembre del 2017 observé un adulto capturando un escorpión bicolor del Pacífico (Centruroides bicolor, Buthidae) en un parche de bosque en Tinamastes de Pérez Zeledón, al sur de la provincia de San José. La serpiente lo muerde y sostiene por el abdomen hasta que el veneno hace efecto, y luego lo traga (Fig. 1). Estas serpientes son inmunes a las repetidas picaduras defensivas del escorpión.

\section{REFERENCIAS}

Solórzano, A. (2004). Serpientes de Costa Rica: Distribución, Taxonomía e Historia Natural. Santo Domingo, Heredia: Editorial Instituto Nacional de Biodiversidad (INBio).

Solórzano, A., \& Greene, H. W. (2011). Predation in nature by a scorpion hunter Stenorrhina freminvillei (Serpentes: Colubridae). UNED Research Journal, 4(1), 31-32. doi: 10.22458/urj.v4i1.130

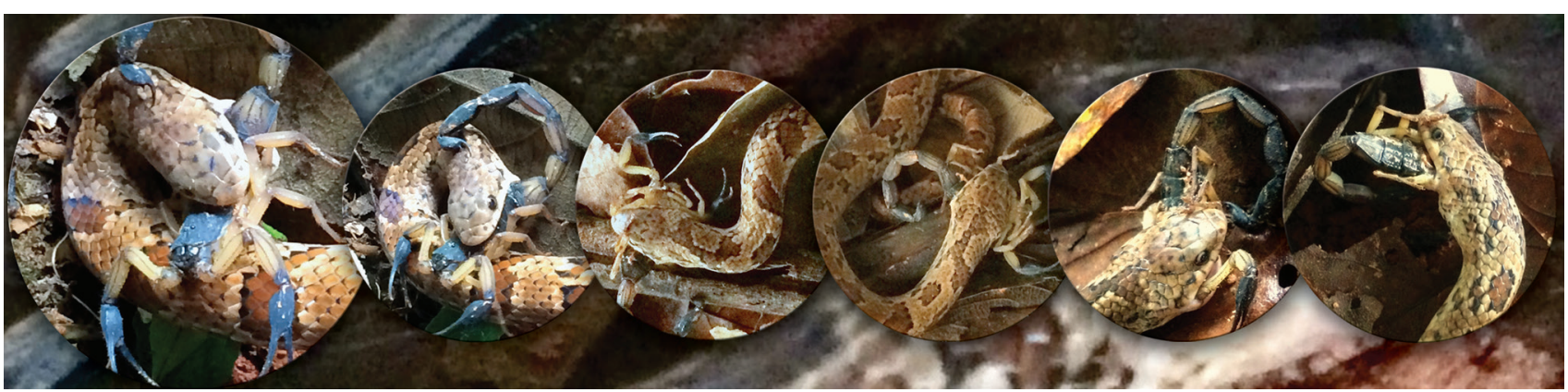

Fig. 1. Stenorrhina degenhardtii consumiendo un Centruroides bicolor. 